\title{
Chimeric Antimicrobial Peptides Exhibit Multiple Modes of Action
}

\author{
Laszlo Otvos Jr., ${ }^{1,4}$ Christine Snyder, ${ }^{1}$ Barry Condie, ${ }^{1}$ Philippe Bulet, ${ }^{2}$ and John D. Wade ${ }^{3}$
}

(Accepted September 25, 2004)

Pyrrhocoricin and drosocin, representatives of the short, proline-rich antimicrobial peptide family kill bacteria by inactivating the bacterial heat shock protein DnaK and inhibiting chaperone-assisted protein folding. The molecular architecture of these peptides features an $\mathrm{N}$-terminal DnaK-binding half and a C-terminal delivery unit, capable of crossing bacterial membranes. Cell penetration is enhanced if multiple copies of pyrrhocoricin are conjugated. To obtain drug leads with improved antimicrobial properties, and possible utility as therapeutic agents, we synthesized chimeric dimers, in which pyrrhocoricin's potent DnaK-binding domain was connected to drosocin's superior cell penetrating module. Indeed, the new constructs not only exhibited enhanced in vitro antibacterial properties against the originally sensitive strains Escherichia coli, Klebsiella pneumoniae and Salmonella typhimurium, but also showed activity against Staphylococcus aureus, a bacterial strain resistant to native pyrrhocoricin and drosocin. The improved antimicrobial profile could be demonstrated with assays designed to distinguish intracellular or membrane activities. While a novel mixed pyrrhocoricin-drosocin dimer and the purely pyrrhocoricinbased old dimer bound $E$. coli DnaK with an identical $4 \mu \mathrm{M} K_{\mathrm{d}}$, the mixed dimers penetrated a significantly larger number of $E$. coli and $S$. aureus cells than the previous analogs and destroyed a larger percentage of bacterial membrane structures. Toxicity to human red blood cells could not be observed up to the highest peptide concentration tested, $640 \mu \mathrm{M}$. In addition, repetitive reculturing of $E$. coli or $S$. aureus cells with sublethal concentrations of the mixed dimer did not result in resistance induction to the novel peptide antibiotic. The new concept of pyrrhocoricin-drosocin mixed dimers yields antibacterial peptide derivatives acting with a multiple mode of action, and can serve as a useful addition to the current antimicrobial therapy repertoire.

KEY WORDS: Cell penetration; DnaK binding; drosocin; growth inhibition; membrane disintegration; pyrrhocoricin; resistant bacteria; stability; toxicity.

\footnotetext{
${ }^{1}$ The Wistar Institute, 3601 Spruce Street, Philadelphia, PA, 19403, USA.

${ }^{2}$ Atheris Laboratories, Geneva, Switzerland.

${ }^{3}$ Howard Florey Institute, Melbourne, Australia.

${ }^{4}$ To whom correspondence should be addressed: Laszlo Otvos, The Wistar Institute, 3601 Spruce Street, Philadelphia, PA, 19403, USA. Tel: +1-215-898-3772; Fax: +1-215-898-5821; e-mail: otvos@wistar.upenn.edu
}

\begin{abstract}
Abbreviations: Chex, 1-amino-1-cyclohexane carboxylic acid; Dab, 2,4-diamino-butyric acid; DIC, differential interference contrast; Hsp, heat shock protein; LPS, lipopolysaccharide; MALDI, matrix-assisted laser desorption/ionization; MHB, Muller-Hinton broth; MIC, minimal inhibitory concentration; PBS, phosphate buffered saline; Pip, 4-amino-piperidine-4-carboxylic acid; RPHPLC, reversed-phase high performance liquid chromatography; TNF, tumor necrosis factor.
\end{abstract}




\section{INTRODUCTION}

It has been increasingly recognized that native antibacterial peptides are multifunctional molecules (Friedrich et al. 2000). In their defense mechanism insects mainly rely on innate immunity (Boman 1995), when antimicrobial peptides can be detected in the hemolymph as early as $2-4 \mathrm{~h}$ after a septic injury (Meister et al. 1997). These peptides are remarkably potent antibacterial compounds. In response to an experimental infection of Drosophila melanogaster, the overall hemolymph concentration of eight inducible antimicrobial peptides reaches high micromolar or low millimolar values, half of which is accounted for by the antifungal molecule drosomycin, and the other half by seven additional antibacterial or/and antifungal compounds (Uttenweiler-Joseph et al. 1998). Recent studies suggest that cationic antimicrobial peptides, once thought to have only bacterial killing properties, are also potent stimulators of the innate immune system (DiNardo et al. 2003). Peptide LL-37 prevents lipopolysaccharide (LPS)-induced production of tumor necrosis factor (TNF)- $\alpha$ in vitro and protects mice from endotoxic shock (Scott et al. 2002). Additional functions of LL37 include being chemotactic for human peripheral blood neutrophils, monocytes and T-cells (Yang et al. 2000). Due to the inflammatory properties of other types of antimicrobial peptides, the current challenge is to enhance innate responses without harmful immunological side effects (Finlay and Hancock 2004).

In the early-mid-90s, cationic antimicrobial peptides were generally described as membrane-active agents. A direct correlation between antibiotic effect and membrane disruption has been found for mammalian and insect defensins, magainins from frogs and cecropins from insects (Steiner et al. 1988; Cociancich et al. 1993; Wimley et al. 1994; Ludtke et al. 1995). However the question is still open whether membrane disintegration is the only mechanism by which these peptides kill bacteria, the peptides have various intracellular targets, or if both mechanisms play roles in the killing process. Individual peptides, selected from each of the four structural classes of the antimicrobial peptide families, vary widely in their ability to depolarize the cytoplasmic membrane potential of the most frequent test microorganism Escherichia coli, with certain peptides being unable to cause depolarization at the minimal inhibitory concentration (MIC), and others causing maximal depolarization below the MIC value (Wu et al. 1999). In support, an increasing number of reports identify various intracellular functions and macromolecules as targets of antibacterial peptides (for reviews see Refs. Andreu and Rivas 1998; Cudic and Otvos 2002; Devine and Hancock 2002). The truth probably lies in a multifunctional mode of action. The peptides first enter the bacteria, they either lyse the membrane or leave the membrane structure intact, depending upon the fine amino acid composition, and some of the antibacterial peptides ultimately meet their intracellular targets (Gallo and Huttner 1998). When prolines are inserted into the sequences of $\alpha$-helical antimicrobial peptides, the peptides' ability to permeabilizing the cytoplasmic membrane of E. coli decreases substantially as the function of the number of proline residues incorporated (Zhang et al. 1999). In this regard, it is intriguing that some of the most active native antibacterial peptides, at least those against selected Gram-negative pathogens, belong to the proline-rich peptide family (Otvos et al. 2000a).

Medium-sized proline-rich antibacterial peptides have been isolated from Hymenoptera, Lepidoptera, Hemiptera and Diptera. The most studied members are drosocin from D. melanogaster (Bulet et al. 1993) (Table I), pyrrhocoricin from the European sapsucking bug Pyrrhocoris apterus (Cociancich et al. 1994), apidaecins from the honeybee (Casteels et al. 1989), and formaecin from the ant Myrmecia gulosa (Mackintosh et al. 1998). Both native pyrrhocoricin and drosocin show some selectivity towards

Table I. Sequences of Proline-rich Antimicrobial Peptides of This Report

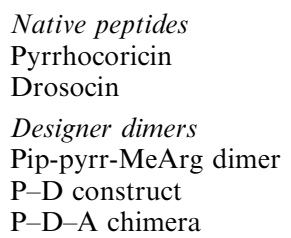

H-Val-Asp-Lys-Gly-Ser-Tyr-Leu-Pro-Arg-Pro-Thr-Pro-Pro-Arg-Pro-Ile-Tyr-Asn-Arg-Asn- $\mathrm{NH}_{2}$ H-Gly-Lys-Pro-Arg-Pro-Tyr-Ser-Pro-Arg-Pro-Thr-Ser-His-Pro-Arg-Pro-Ile-Arg-Val-NH

(H-Pip-Asp-Lys-Gly-Ser-Tyr-Leu-Pro-Arg-Pro-Thr-Pro-Pro-Arg-Pro-Ile-Tyr-Asn-MeArg-Asn) $)_{2}-\mathrm{Dab}-\mathrm{NH}_{2}$ (H-Pip-Asp-Lys-Gly-Arg-Tyr-Leu-Pro-Arg-Pro-His-Pro-Arg-Pro-Ile-Tyr-MeArg) ${ }_{2}$-Dab-NH ${ }_{2}$ (H-Chex-Asp-Lys-Gly-Arg-Tyr-Leu-Pro-Arg-Pro-His-His-Pro-Arg-Pro-Ile-Tyr-Arg) ${ }_{2}$-Dab-NH ${ }_{2}$

Where Dab is 2,4-diamino-butyric acid, MeArg is N-methyl-arginine, Pip is 4-amino-piperidine-4-carboxylic acid and Chex is 1-amino-1cyclohexane-carboxylic acid. 
Gram-negative organisms, mostly from the Enterobacteriaceae family killing $E$. coli, Salmonella typhimurium, Klebsiella pneumoniae and Agrobacterium tumefaciens in the mid nM-low $\mu \mathrm{M}$ concentration range (Bulet et al. 1996; Hoffmann et al. 1999). Additional Gram-negative drosocin susceptible strains include Enterobacter cloacae and Erwinia carotovora carotovora. Pyrrhocoricin is active against Haemophilus influenzae (Cudic and Otvos 2002). Both peptides kill the Gram-positive bacterium Micrococcus luteus, and pyrrhocoricin shows weak activity against two additional Gram positives, Bacillus megaterium and Aerobacter viridans. The short, proline-rich peptides in their native form do not appear to kill the major Gram-positive threats to humans, such as Staphylococcus aureus, Streptococcus pneumoniae or Streptococcus pyogenes. They are also inactive against fungi. A series of small proline-rich peptides were isolated from bees, and they are collectively called apidaecins (Casteels et al. 1989). These are 18-20 residue-long peptides with highly conserved carboxy termini. The N-terminal substitutions feature both conservative and non-conservative residue changes. The constant domains are considered responsible for the general antibacterial activity, and the variable domains for the bacteria-specific activity spectrum. Indeed, huge activity differences can be found among the apidaecin peptides, with the peptides from the honeybee killing Yersinia enterocolitica but not affecting Campylobacter jejuni, and the analogs isolated from the wasps acting in exactly the opposite way (Casteels et al. 1994).

Based on studies with D-enantiomers, apidaecin, drosocin and pyrrhocoricin were suggested to act with a certain stereospecificity on a bacterial target protein (Casteels and Tempst 1994; Bulet et al. 1996; Hoffmann et al. 1999). The proposed mechanism by which apidaecin kills bacteria involves an initial encounter of peptide with an outer membrane component, followed by a specific and essentially irreversible engagement with a receptor/docking molecule in the cells. In the final step, the peptide is translocated into the cell interior where it meets its ultimate target, one or more components of the protein synthesis machinery (Castle et al. 1999). When identifying the biopolymers involved in this cascade, we observed that pyrrhocoricin, drosocin and apidaecin bind to bacterial LPS and the $70 \mathrm{kDa}$ heat shock protein (Hsp) DnaK in a specific manner, while the binding to the $60 \mathrm{kDa}$ bacterial chaperonine GroEL is non-specific (Otvos et al. 2000b). Later we studied the mechanism of action of the proline- rich antimicrobial peptides especially that of pyrrhocoricin, and their binding sites to E. coli DnaK. According to these studies, biologically active pyrrhocoricin made of L-amino acids inhibits the ATPase activity of a recombinant form of this Hsp70 variant (Kragol et al. 2001), while the inactive D-enantiomer or membrane-active antibacterial peptides such as cecropin A or magainin 2 fail to inhibit DnaK-mediated phosphate release from ATP. Pyrrhocoricin and drosocin also inhibit DnaK-mediated refolding of nascent proteins in $E$. coli cells as opposed to mostly membrane-acting antimicrobial peptides that do not show this effect (Kragol et al. 2001). A combination of DnaK binding, cell penetration and enzyme inhibition studies identified Asp2, Tyr6, Leu7 and Arg9 in pyrrhocoricin as binding sites to bacterial DnaK, the C-terminal half of the peptide as the cell penetrating module, and the interspersed proline residues as a motif responsible for the maintenance of structural integrity (Bower et al. 2004).

While pyrrhocoricin shows an increased in vitro efficacy against Gram-negative bacterial strains than drosocin, the latter peptide demonstrates a somewhat broader activity spectrum. These properties are likely due to the more robust pharmacophore of pyrrhocoricin and the more potent cell-penetrating domain of drosocin, at least at the monomeric peptide level (Bencivengo et al. 2001). Slight changes in the peptide sequence, all including incorporation of additional positively charged amino acid residues, can change pyrrhocoricin's predominant mode of action from DnaK inhibition to membrane disintegration (Bencivengo et al. 2001; Bower et al. 2003). The additional positive charges promote interaction of the peptide with bacterial membranes to a point when harmless cell penetration turns into membrane depolarization. Another way to increase the level of peptide interaction with bacterial membranes and thus, to improve the antimicrobial properties, is dimerization of the antimicrobial peptide molecules. Indeed, designer pyrrhocoricin dimers, when two peptide molecules are connected via a C-terminal diamino-carboxylic acid residue, exhibit markedly improved in vitro antimicrobial properties (Cudic et al. 2002). The enhanced in vitro antibacterial properties are reflected in remarkable in vivo protective effects in mouse models of pneumonia and pyelonephritis (Cudic et al. 2002; Cudic et al. 2003). However, even the most active pyrrhocoricin analog, the Pip-pyrr-MeArg dimer (Table I), is suboptimal as a clinical candidate as is indicated in its inability to kill bacteria in full-strength media used customarily for vigorous propagation of 
bacterial cultures, the broth of choice of the microbiology literature (Cudic et al. 2002; Cudic et al. 2003). The Pip-pyrr-MeArg dimer exhibits poor in vivo efficacy if systemic bacteremia is induced in mice by infecting them with bacterial colonies exceeding $10^{6} \mathrm{cfu}$ (mortality rather than morbidity).

In the current study we investigate the antimicrobial and cell penetration properties of mixed pyrrhocoricin-drosocin dimers. First, as a practical goal, we wanted to generate antibacterial peptides with further improved in vitro efficacy for ensuing pharmaceutical development. Second, on a purely theoretical basis, we wanted to document that designer antimicrobial peptides are able to kill bacteria by a dual mode of action: DnaK inhibition and/or membrane disintegration. Since bacteria have to modify their genetic composition to each individual mode of action to develop resistance to any given antibiotic, such a combinatorial therapy approach will be extremely useful to fight bacterial resistance in the long run.

\section{MATERIALS AND METHODS}

\section{Peptide Synthesis}

Amino acids protected with 9-fluorenyl-methoxy-carbonyl group (Fields and Noble 1990), were used for peptide synthesis. The peptide chain assembly was carried out on a Rainin PS3 automated synthesizer. After trifloroacetic acid cleavage, peptides were purified by reversed-phase high performance liquid chromatography (RP-HPLC) in a water/acetonitrile/trifluoroacetic acid elution system until matrix-assisted laser-desorption/ionization (MALDI) mass spectra revealed only single species.

\section{Fluorescence Polarization}

Recombinant DnaK protein was serially diluted in Tris-buffer (pH 7.4) in $50 \mu \mathrm{L}$ final volume in $6 \times 50 \mathrm{~mm}$ disposable glass borosilicate tubes. The fluoresceinated peptides were added to each tube in a $50 \mu \mathrm{L}$ aliquot to a final concentration of $1-4 \mathrm{nM}$ and the tubes were incubated at $37^{\circ} \mathrm{C}$ for $5 \mathrm{~min}$. The extent of fluorescence anisotropy was measured on a Beacon 2000 fluorescence polarization instrument (PanVera, Madison, WI) and was calculated as millipolarization values. The filters used were $485 \mathrm{~nm}$ excitation and $535 \mathrm{~nm}$ emission with $3 \mathrm{~nm}$ band width. The $K_{\mathrm{d}}$ values were calculated after curve fitting with non-linear logistical transition by the LevenbergMarquardt algorithm within the SlideWrite software package.

\section{Antibacterial Assay}

Antibacterial liquid growth inhibition assays were performed using sterile 96-well plates (Nunc F96 microtiter plates) in a final volume of $100 \mu \mathrm{L}$ as described previously (Cudic et al. 2002). Briefly, $90 \mu \mathrm{L}$ of a suspension of a midlogarithmic phase bacterial cultures at an initial absorbance at $600 \mathrm{~nm}$ of 0.001 in full-strength or diluted Muller-Hinton Broth (MHB) was added to $10 \mu \mathrm{L}$ of serially diluted peptides dissolved in sterilized water. The final peptide concentration was $40 \mu \mathrm{M}$. Cultures were incubated at $37^{\circ} \mathrm{C}$ for $20 \mathrm{~h}$ without shaking. Growth inhibition was measured by recording the absorbance at $600 \mathrm{~nm}$ using a microplate reader.

\section{Cell Penetration}

In order to study the ability of peptide derivatives to enter E. coli SEQ102 (ATCC BAA457) or S. aureus 655 (ATCC 27660) cells fluorescein-labeled peptides were added to bacterial cultures at final concentrations of $5 \mu \mathrm{g} / \mathrm{mL}$. The cells were allowed to acquire the peptides for $1 \mathrm{~h}$ at $37^{\circ} \mathrm{C}$. Excess substrate was then removed and the cells were washed extensively with phosphate buffered saline (PBS), pH 6.8. The cells were fixed with PBS containing $1 \%$ paraformaldehyde and visualized using a Leica TCS SPII laser scanning confocal microscope. To check for total number of bacterial cells from the same preparations, the cells were also detected with differential interference contrast microscopy (DIC) and counted. This technique produces a monochromatic shadow-cast image (such as shown in Fig. 4) that effectively displays the gradient of optical paths for both high and low spatial frequencies present in the specimens.

\section{Bacterial Viability Assay}

E. coli SEQ102 or S. aureus 655 cells were grown in fullstrength $\mathrm{MHB}$ at $37^{\circ} \mathrm{C}$ to midlogarithmic phase. The cells were then allowed to acquire the peptide for $1 \mathrm{~h}$ at $37^{\circ} \mathrm{C}$. The final concentrations of the peptides were 5 and $20 \mu \mathrm{M}$, respectively. Solutions were treated with $3 \mu \mathrm{L}$ LIVE/DEAD ${ }^{\circledR}$ BacLight $^{\text {TM }}$ stain (Molecular Probes Inc., Eugene, OR). Samples were incubated in the dark for $15 \mathrm{~min}$ prior to analysis. Stained samples for microscopy analysis were passed through $0.2 \mu \mathrm{m}$ black, polycarbonate membrane filters supported by a $25 \mathrm{~mm} 0.45 \mu \mathrm{m}$ mixed cellulose ester filter. Bacteria retained on the filter were then washed with sterile water to remove any unbound stain. Following the wash step, the polycarbonate filters were transferred to a glass microscope slide. A drop of Vectashield mounting medium was applied to the filter. A glass cover slip was then applied. The microscope slides were photographed with a $100 \times$ plan apo 1.4 N.A. oil lens on a Nikon E600 upright microscope with a SPOT RT Slider digital camera. The images were analyzed using Image Pro Plus software (MediaCybernetics, Coral Springs, MD).

\section{Hemolysis}

One and a half milliliter of human blood was centrifuged at $3000 \mathrm{rpm}$ for $5 \mathrm{~min}$. Ten microliter of the pellet was added to $490 \mu \mathrm{L}$ PBS to create a $1 \%$ red blood cell stock solution. Fifty microliter of this suspension was mixed with $50 \mu \mathrm{L}$ of $10 \mu \mathrm{M}-$ $1.28 \mathrm{mM}$ aqueous peptide solutions and the mixtures were incubated for $1 \mathrm{~h}$ at $37^{\circ} \mathrm{C}$ without shaking. After incubation, the cells were centrifuged again at $3000 \mathrm{rpm}$ for $5 \mathrm{~min}$, and the absorbance of the supernatant read at 405 and $485 \mathrm{~nm}$.

\section{RESULTS}

\section{Antimicrobial Peptide Design and Synthesis}

Our current lead compound is the Pip-pyrr-MeArg dimer (Table I), a dimeric pyrrhocoricin analog 
containing three non-natural amino acid residue modifications. To improve cell penetration, native pyrrhocoricin is dimerized via building the peptide on a C-terminal 2,4-diamino-butyric acid (Dab) scaffold. The $\mathrm{N}$-terminal valine residue in native pyrrhocoricin is replaced by 4-amino-piperidine-4-carboxylic acid (Pip) to avoid aminopeptidase cleavage, decrease interaction with the conventional substrate-binding pocket of mammalian Hsp70 (to eliminate high dose toxicity to infected mammals) and to further improve bacterial cell penetration (additional positive charge) (Cudic et al. 2002). The Asn-Arg bond near the $\mathrm{C}$-terminus is the main pyrrhocoricin cleavage site in mammalian serum (Hoffmann et al. 1999), and to increase the half-life this bond is protected by N-methylation. In our earlier studies, we optimized the synthetic details of similar pyrrhocoricin dimers (Cudic et al. 2002). As single-chain drosocin appears to exhibit better cell penetrating properties than native pyrrhocoricin, our initial plan was to prepare the exact drosocin-based analog of the Pip-pyrr-MeArg dimer. In spite of our repeated efforts, mass spectroscopy indicated that our crude products did not contain the expected peptide species. This coincides with our previous findings relative to the synthesis opportunities of pyrrhocoricin and drosocin derivatives. While multiple synthesis of an Ala-scan of pyrrhocoricin (Kragol et al. 2002) yielded all analogs in acceptable purity, the synthesis failed for approximately half of the drosocin Ala-scan peptides.

Learning from this experience, we decided to prepare a mixed pyrrhocoricin-drosocin dimer (P-D construct). In the $\mathrm{P}-\mathrm{D}$ construct, we retained the $\mathrm{N}$ terminal 10 residues of the Pip-pyrr design that contains the putative DnaK-binding motif, and added drosocin's C-terminal delivery module with the last arginine $\mathrm{N}$-methylated, MeArg (Table I). Just like for the Pip-pyrr-MeArg dimer, the P-D construct was built up on a Dab scaffold, which replaced the native C-terminal Val in drosocin. We made two additional changes: to further improve cell penetration, the apparently functionless Ser5 was replaced with the positively charged Arg and the C-terminal Tyr in pyrrhocoricin was inserted into the analogous position in drosocin (between Ile17 and Arg18) in order to provide additional contact points to the lipidic portions of bacterial membranes. Native membraneactive antimicrobial peptides utilize an alternating positively charged - hydrophobic residue architecture to depolarize bacterial membranes (Otvos 2000). In contrast to the purely drosocin-based dimer, the $\mathrm{P}-\mathrm{D}$ construct could be prepared with one dominant peak on the mass spectrum. However, this peptide species represented an analog with the MeArg protecting Mtr group still attached to one of the guanidine sidechains (4613 $\mathrm{m} / \mathrm{z}$ compared to the calculated molecular mass of $4403 \mathrm{Da}$ ). Repeated trifluoroacetic acid treatments were unable to remove the Mtr group. Neither our inability to remove one of the MeArg protecting groups nor the cleavage of the second Mtr moiety is surprising: the MeArg residue is located closer to the asymmetrical Dab scaffold than does the analogous MeArg in the parent Pip-pyrr-MeArg dimer, and thus is subject of steric hindrance to ensuing reactions (Urge and Otvos 1995). A second, less dominant though potentially troubling synthetic problem for industrial scale production was the lower-than-average coupling yield of the $\mathrm{N}$-terminal Fmoc-Pip(Boc)-OH residue.

Therefore in the final product, the $\mathrm{P}-\mathrm{D}-\mathrm{A}$ (pyrrhocoricin-drosocin-apidaecin) chimera (Table I), we eliminated the N-methyl backbone protection and replaced the Pip residue with Chex, 1-amino-1cyclohexane carboxylic acid, a cyclic valine mimic without the extra positive charge in the ring. Pyrrhocoricin dimers with Chex as an $\mathrm{N}$-terminal residue are remarkably active both in vitro and in vivo (Cudic et al. 2002). To compensate for the loss of a positive charge, an extra histidine residue was inserted between the pyrrhocoricin-based $\mathrm{N}$-terminal and the drosocin-based C-terminal fragments. This idea came from the antimicrobial activity of pyrrhocoricin and drosocin analogs, and sequence comparison with the apidaecins: Thr11 in pyrrhocoricin and drosocin can be freely substituted without a loss in the antibacterial activity (Kragol et al. 2002), have no apparent function (Bower et al. 2004), and indeed, are replaced with His in the apidaecin sequences (Casteels et al. 1989). With its positive charge and hydrophobic character, His is an ideal residue to increase the interaction of antimicrobial peptides with bacterial membrane structures. The synthesis of the $\mathrm{P}-\mathrm{D}-\mathrm{A}$ chimera proceeded effortlessly in a reproducible manner, even with single couplings throughout. After cleavage the expected peptide species (measured average molecular mass $4647 \mathrm{~m} / z$, compared to a calculated molecular mass of $4647 \mathrm{Da}$ ) could be purified in high yield.

\section{Antibacterial Activity In Vitro}

The antibacterial activities of the pyrrhocoricindrosocin chimeras were tested against four strains of three Pip-pyrr-MeArg susceptible bacteria, E. coli 
SEQ102, K. pneumoniae K6, K. pneumoniae 1296 and $S$. typhimurium $\mathrm{S} 2$, as well as against the pyrrhocoricin non-susceptible strain $S$ aureus 655 . These represent historical bacterial strains with early resistance to selected antibiotics (K. pneumoniae K6, $S$. typhimurium $\mathrm{S} 2$ and $S$. aureus 655 ) and newer multidrug resistant isolates from the urinary tract of infected patients (E. coli SEQ102 and K. pneumoniae 1296) (Cudic et al. 2002; Cudic et al. 2003). Antibacterial peptides with intracellular targets are active only when the assay is run in diluted growth medium, most likely because the salt content of full-strength media used to quickly propagate bacterial cultures blocks the positive charges needed for membrane interaction and hence cell penetration (Cudic et al. 2002). By the same token, the growth curves without any antibiotics indicate that bacteria grown in diluted MHB are not as healthy as they are in full-strength MHB. Therefore, we tested the efficacy of the peptides in both one-quarter strength MHB and in the full-strength version. Because all the above-listed test strains are sensitive to fluoroquinolones and resistant to $\beta$-lactams (Cudic et al. 2002; Cudic et al. 2003), ciprofloxacin was used as positive and amoxicillin as negative controls.

As found earlier, native pyrrhocoricin was inactive or very weakly active against all strains in fullstrength MHB, and exhibited only mediocre activity against the Gram-negatives in one-quarter strength MHB (Table II). The Pip-pyrr-MeArg dimer was similarly inefficient in full-strength MHB, but killed Gram-negative Enterobacteriaceae very efficiently when the activity was tested in diluted medium (Table II and Fig. 1). In line with DnaK disintegration as a predominant mode of action, this pyrrhocoricin-based dimer was inactive against $S$. aureus, a strain that does not share DnaK protein sequence homology with $E$. coli at the pyrrhocoricin-binding D-E helix region. It needs to be mentioned that native, single-chain drosocin is similarly inactive against $S$. aureus strains in both full-strength and diluted media (Bulet et al. 1996). The pyrrhocoricin-drosocin dimer chimeras demonstrated superior activity against Enterobacteriaceae even in full-strength MHB. Their activity against E. coli was indistinguishable in full-strength or diluted media indicating that penetration into E. coli cells was not inhibited any longer. While they could not kill $S$. aureus in fullstrength MHB, they exhibited good activity in onequarter strength MHB (Fig. 2), an ambition none of our previous pyrrhocoricin or drosocin derivatives could achieve. This was our first indication that the pyrrhocoricin-drosocin chimeras kill bacteria with a mode of action different than that utilized by other proline-rich antibacterial peptides. If any distinction can be made, the $\mathrm{P}-\mathrm{D}-\mathrm{A}$ chimera appeared to be slightly more active than the $\mathrm{P}-\mathrm{D}$ construct.

\section{DnaK Binding}

Our next goal was to document that the superior antimicrobial properties of the $\mathrm{P}-\mathrm{D}-\mathrm{A}$ chimera compared to the Pip-pyrr-MeArg dimer was due to better binding to the target DnaK protein. N-terminally fluorescein-labeled derivatives of these peptides were incubated with recombinant E. coli DnaK and the binding was recorded on a fluorescence polarimeter. Both antibacterial peptide derivatives bound E. coli DnaK in a concentration-dependent manner (Fig. 3). The $K_{\mathrm{d}}$ values of this set of assays, equally around $4 \mu \mathrm{M}$, are almost identical to that we obtained earlier for the Pip-pyrr-MeArg dimer - E. coli

Table II. Minimal Inhibitory Concentrations (in $\mu \mathrm{M}$ ) of Antibiotics Against Various Pathogens

\begin{tabular}{|c|c|c|c|c|c|c|}
\hline \multirow[b]{3}{*}{ Antibiotics } & \multicolumn{6}{|c|}{ Bacterial strains } \\
\hline & \multicolumn{2}{|c|}{ E. coli SEQ102 } & \multicolumn{2}{|c|}{ K. pneumoniae $\mathrm{K} 6$} & \multicolumn{2}{|c|}{ S. aureus 655} \\
\hline & $\begin{array}{c}\text { Full-strength } \\
\text { MHB }\end{array}$ & $\begin{array}{l}\text { 1/4 strength } \\
\text { MHB }\end{array}$ & $\begin{array}{c}\text { Full-strength } \\
\text { MHB }\end{array}$ & $\begin{array}{l}\text { 1/4 strength } \\
\text { MHB }\end{array}$ & $\begin{array}{l}\text { Full-strength } \\
\text { MHB }\end{array}$ & $\begin{array}{l}1 / 4 \text { strength } \\
\text { MHB }\end{array}$ \\
\hline Pyrrhocoricin & $>40$ & 10 & $>40$ & 40 & $>40$ & $>40$ \\
\hline Pip-pyrr-MeArg dimer & 20 & 1.2 & $>40$ & 2.5 & $>40$ & $>40$ \\
\hline $\mathrm{P}-\mathrm{D}$ construct & 5 & 2.5 & 20 & 5 & $>40$ & 10 \\
\hline P-D-A chimera & 2.5 & 5 & 10 & 2.5 & $>40$ & 5 \\
\hline Amoxicillin & $>40$ & $>40$ & $>40$ & $>40$ & $>40$ & $>40$ \\
\hline Ciprofloxacin & $<0.3$ & $<0.3$ & $<0.3$ & $<0.3$ & $<0.3$ & $<0.3$ \\
\hline
\end{tabular}

The liquid growth inhibition assays were run in full-strength or diluted Muller-Hinton broth overnight at $37^{\circ} \mathrm{C}$. The MIC values of the dimeric pyrrhocoricin-drosocin-apidaecin chimera against the multidrug resistant strains K. pneumoniae 1296 and S. typhimurium S2 in fullstrength MHB are 20 and $2.5 \mu \mathrm{M}$, respectively. 

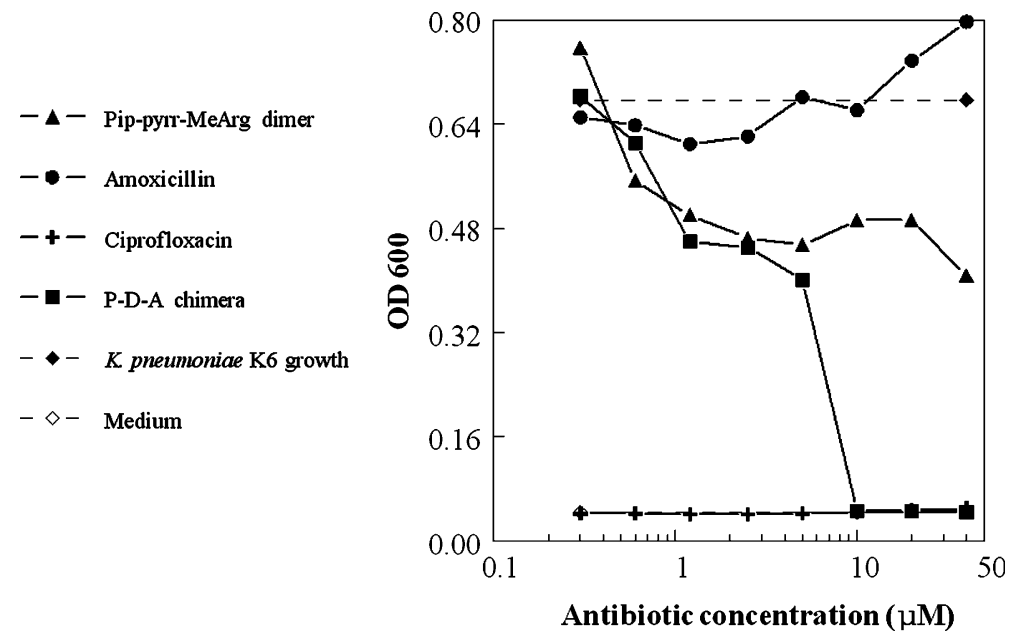

Fig. 1. In vitro activity of pyrrhocoricin dimers and control antibiotics against Klebsiella pneumoniae K6. The standard broth dilution susceptibility assay was run in full-strength Muller-Hinton broth overnight at $37^{\circ} \mathrm{C}$.
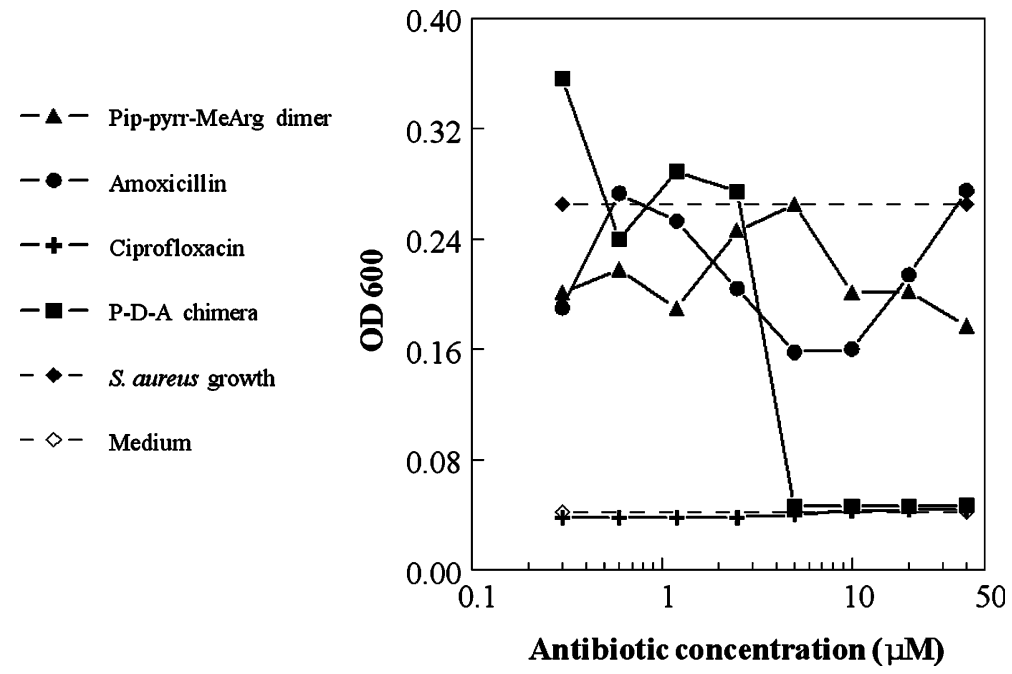

Fig. 2. In vitro activity of pyrrhocoricin dimers and control antibiotics against $S$. aureus 655 . The standard broth dilution susceptibility assay was run in one-quarter strength Muller-Hinton broth overnight at $37^{\circ} \mathrm{C}$.

DnaK interaction (approximately $3.5 \mu \mathrm{M}$, Ref. Bower et al. 2003). The minor alteration in the $K_{\mathrm{d}}$ figure from assay to assay reflects solubility problems of pyrrhocoricin - DnaK protein complexes during in vitro biological assay conditions (Chesnokova et al. 2004). We also attempted to record binding of the same fluorescein-labeled peptides to synthetic E. coli or S. aureus DnaK D-E helix fragments, but no fluorescence anisotropy could be observed. This was not surprising as in this case, as opposed to our earlier assays with smaller, monomeric peptides (Kragol et al. 2002), the size of the tracer exceeded the size of the test compound, and little, if any, change in the spinning speed of the fluorescein- labeled tracer could be expected after mixing and upon peptide-peptide binding.

\section{Entry into Bacterial Cells}

For measuring the level of cell penetration, we used two microscopy techniques. Upon incubation with bacteria, $\mathrm{N}$-terminal fluorescein-derivatives enter cells and stain all the compartments where they are distributed. Homogenous cell staining indicates full penetration, labeling only the cell surface indicates temporary, weak interactions with the phospholipid bilayer. In the dual fluorochrome assay bacteria are incubated with the test compounds and 


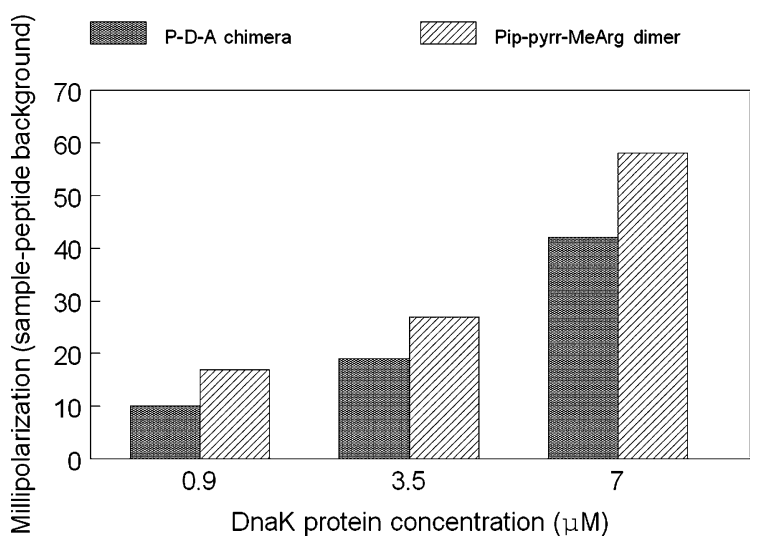

Fig. 3. Binding of N-terminally fluorescein-labeled peptide dimers to recombinant E. coli DnaK protein. The interaction of the peptides and the protein was studied by fluorescence polarization.

are stained for healthy or damaged membranes. Thus, this measure is a reflection of the ability of the test compounds to cause leakage in the membrane structure. Both assays were used to identify differences in the activity of the $\mathrm{P}-\mathrm{D}-\mathrm{A}$ chimera and the Pip-pyrr-MeArg dimer on bacterial membranes. In the cell penetration assay, the fluorescein-labeled Pippyrr-MeArg dimer stained approximately $30 \%$ of E. coli cells (Fig. 4). For the $\mathrm{P}-\mathrm{D}-\mathrm{A}$ chimera this value was close to $100 \%$, indicating a significantly increased ability of the pyrrhocoricin-drosocin mixed dimer to penetrate bacteria than the purely pyrrhocoricin-based analog. For S. aureus, the cell penetration values were $3 \%$ and $10 \%$ for the Pip-pyrrMeArg dimer or the P-D-A chimera, respectively. The ability of the peptides to enter bacteria was identical regardless of whether the cells were grown individually or clumped together (Fig. 4). Every cell penetrated was stained homogenously, indicating full distribution in the intracellular milieu. While Fig. 4 shows only one-piece cells for quantitation of the results, many fully damaged cells, destroyed by the antimicrobial peptides, could be observed under the microscope. The number of dead cells was higher when cultures were treated with the $\mathrm{P}-\mathrm{D}-\mathrm{A}$ chimera compared with the Pip-pyrr-MeArg dimer.

The direct effect of the test peptides on bacterial membranes was studied by the dual fluorochrome membrane viability assay. This system provides a method to distinguish between bacteria with healthy or damaged membrane structure. The kit utilizes mixtures of the SYTO 9 green-fluorescent (peak excitation wavelength $480 \mathrm{~nm}$, peak emission wavelength $500 \mathrm{~nm}$ ) nucleic acid stain and the red-fluorescent (peak excitation wavelength $490 \mathrm{~nm}$, peak emission wavelength $635 \mathrm{~nm}$ ) nucleic acid stain, propidium iodide. These stains differ both in their spectral characteristics and in their ability to penetrate bacterial cells. When used alone, the SYTO 9 stain generally labels all bacteria in a population, those with intact membranes and those with damaged membranes. In contrast, propidium iodide penetrates only bacteria with damaged membranes, causing a reduction in the SYTO 9 stain fluorescent when both dyes are present. The ratio of the green and red stained cells can be quantitatively analyzed. Once again, the P-D-A chimera was significantly more successful than the Pip-pyrr-MeArg dimer to depolarize $E$. coli or $S$. aureus bacterial membranes (Fig. 5). In our specific experimental
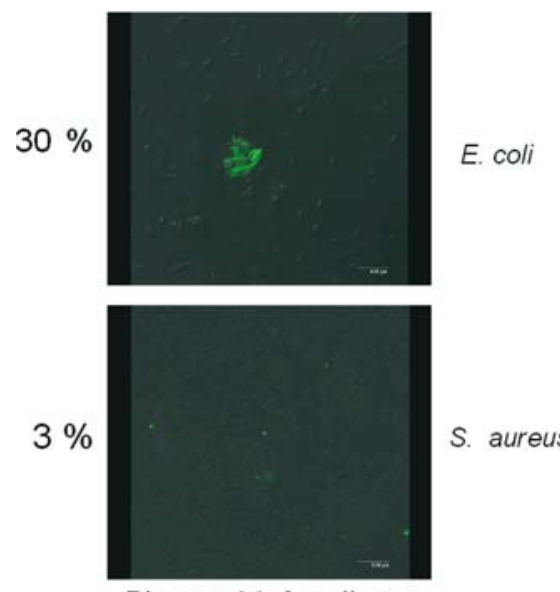

Pip-pyrr-MeArg dimer
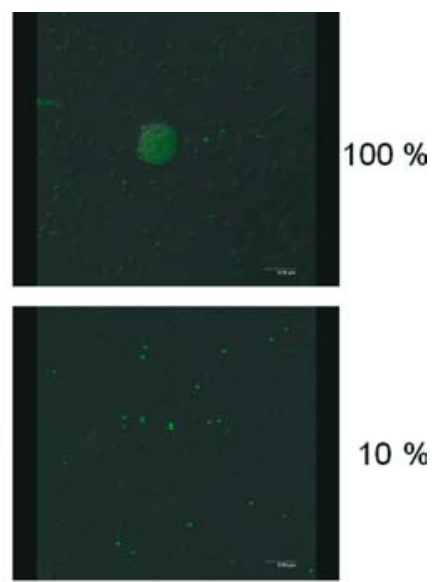

P-D-A chimera

Fig. 4. Penetration of fluorescein-labeled peptides into E. coli SEQ102 and S. aureus 655 cells. The peptides entered the cells and became homogenously distributed in the intracellular space. Percentage of cells containing labeled peptides was calculated based on the total number of cells identified by differential interference contrast. 

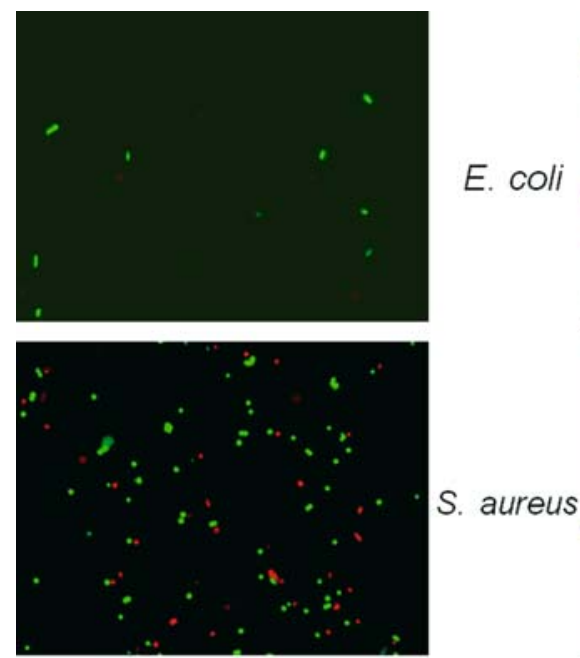

Pip-pyrr-MeArg dimer

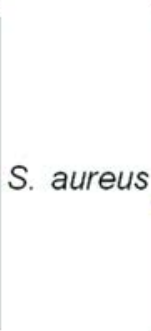

the Pip-pyrr-MeArg dimer and the P-D-A chim

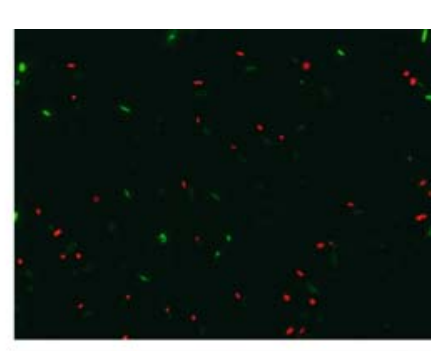

The green stain marks cells with intact membranes; red indicates those with damaged membranes.

conditions, the percentage of cells with damaged membranes upon treatment with the Pip-pyrr-MeArg dimer was $35 \%$ (E. coli) and $36 \%$ (S. aureus). This level of membrane disintegration by itself would not be enough for complete killing of the bacteria. However, the growth of $E$. coli cultures is inhibited at the applied $5 \mu \mathrm{M}$ concentration (Table II) indicating that the inhibition of an intracellular target, in our case the DnaK protein, is sufficient to complete the killing process. The P-D-A chimera caused 50\%$61 \%$ membrane damage to E. coli cells and $52 \%$ damage to $S$. aureus, apparently enough to destroy both bacterial cultures (Table II). Because pyrrhocoricin does not bind to $S$. aureus DnaK (Kragol et al. 2002), all these data suggested that killing of S. aureus cultures by the pyrrhocoricin-drosocin mixed dimer proceeded through membrane disintegration.

\section{Additional Pharmacological Parameters: Toxicity, Stability, Resistance Induction}

In addition to effective killing of bacteria, novel antimicrobials have to show positive pharmacological properties, such as lack of toxicity and resistance induction as well as appropriate stability in biological media. Antimicrobial peptides inhibiting bacterial growth by depolarizing the membrane, such as the cecropins and magainins fall short in one or more of these categories. In particular, excessive activity on bacterial membranes often goes hand in hand with toxicity to mammalian cells (Bower et al. 2003). We also speculated that bacteria can alter their membrane composition to evade the activity of membrane-acting antimicrobial peptides (Cudic et al. 2003). To assess peptide effects on eukaryotes in vitro, we measured mammalian cell toxicity on freshly acquired human red blood cells. In this assay, none of the peptide monomer or dimers (native pyrrhocoricin, Pip-pyrr-MeArg dimer, $\mathrm{P}-\mathrm{D}$ construct or $\mathrm{P}-\mathrm{D}-\mathrm{A}$ chimera) was toxic up to the highest concentrations studied, usually $640 \mu \mathrm{M}$ (Table III). In contrast, magainin 2 caused hemolysis at $160 \mu \mathrm{M}$, near a peptide concentration that was identified as toxic to the mouse kidney-originated COS-7 cells (Cudic et al. 2003). The positive control bee venom mellittin proved to be toxic at $5 \mu \mathrm{M}$, the lowest concentration we used in the assay. In a significant achievement, the observed increased level of penetration into bacterial cells by the pyrrhocoricin-drosocin mixed dimers did not result in noticeable toxicity to mammalian cells. Calculating with a maximum of $3 \mathrm{mg} / \mathrm{kg}$ therapeutic dose (60 $\mu \mathrm{g}$ per mouse) intravenously, if developed as drug candidates, these analogs will offer a remarkable therapeutic index of at least 100.

Although the pyrrhocoricin-drosocin mixed dimers are the most active short, proline-based antimicrobials to date, they might be the source of currently non-existent resistance mechanisms. To study this possibility, E. coli and S. aureus were co-cultured once daily for 10 days with sublethal doses of the P-D-A chimera. The induction of resistant mutants, as indicated by the increase of the 
Table III. Toxicity of Antimicrobial Peptides to Human Red Blood Cells

\begin{tabular}{lc}
\hline Peptide & Lowest toxic concentration in $\mu \mathrm{M}$ \\
\hline Pyrrhocoricin & $>640$ \\
Pip-pyrr-MeArg dimer & $>640$ \\
P-D construct & $>160$ \\
P-D-A chimera & $>640$ \\
Magainin 2 & 160 \\
Mellittin & $<5$ \\
\hline
\end{tabular}

Peptides were incubated with a $1 \%$ erythrocyte suspension and the absorbance of the supernatant was measured at 405 and $485 \mathrm{~nm}$.

MIC values, was studied after passage 5 and 10 not only against the co-culturing antibiotic peptide, but also against a series of other pyrrhocoricin-based or conventional antimicrobial compounds. As Table IV shows, the activity of neither peptidic nor conventional antibiotics changed significantly against either bacteria, suggesting that the improved activity on the cell membrane did not induce major alterations in those regions of the bacterial genome where the test antibiotics exert their activity. These data also indicate that a P-D-A chimera therapy can be followed by treatment with conventional antibiotics if needed without any loss of the potency of the non-peptidic antimicrobials. The day 5 data varied slightly with magainin 2 and kanamycin, on both parallel plates. If this variability was not due to the natural error of the liquid growth inhibition assay, it would indicate that the strong effect of the $\mathrm{P}-\mathrm{D}-\mathrm{A}$ chimera on the membrane actually may induce some membraneassociated resistance that deactivated the other membrane disintegrating peptide antibiotic, magainin 2. In this regard, it is interesting to note that the
P-D-A chimera remained fully active against S. aureus, for which the second killing mechanism, DnaK inhibition is non-existent. The differences are probably found in the way magainin 2 and the pyrrhocoricin-drosocin dimers insert into bacterial membranes. While the proline-less magainin forms $\alpha$-helices in a membrane environment (Wieprecht et al. 2000), the proline-rich peptides pyrrhocoricin or drosocin are unable do so (McManus et al. 1999; Otvos 2000), and it is unlikely their dimeric variants would.

The only problem with the pyrrhocoricin-drosocin chimeras of this report is their low stability in mammalian sera. In our previous study we explained the lack of in vivo efficacy of native drosocin with the fast decomposition in mouse serum (Hoffmann et al. 1999). Actually, we selected pyrrhocoricin for further studies because this peptide shows improved serum stability. In the current study, the purely pyrrhocoricin-based analog, the Pip-pyrr-MeArg dimer, did not lose any in vitro efficacy against $E$. coli (in either $1 / 4$ or full-strength MHB) and retained some activity against $S$. typhimurium when $25 \%$ human serum was added to the wells of the liquid growth inhibition assay, the $\mathrm{P}-\mathrm{D}$ construct or the $\mathrm{P}-\mathrm{D}-\mathrm{A}$ chimera lost a significant amount of efficacy against $E$. coli and became inactive against $S$. typhimurium or $S$. aureus (Table V). Apparently N-methylation of the C-terminal arginine, a major cleavage site in native pyrrhocoricin and drosocin (Hoffmann et al. 1999) did not help improve the serum stability. Overall the P-D construct with backbone protection was no more resistant than the P-D-A chimera lacking a methylated amide bond.

Table IV. Minimal Inhibitory Concentrations (MIC) of Antimicrobials (in $\mu \mathrm{M}$ ) when Bacteria were Repeatedly Cultured with Sublethal Doses of the P-D-A Chimera

\begin{tabular}{|c|c|c|c|c|c|c|}
\hline \multirow[b]{3}{*}{ Antibiotic } & \multicolumn{6}{|c|}{$\operatorname{MIC}(\mu \mathrm{M})$} \\
\hline & \multicolumn{2}{|c|}{ Day 0} & \multicolumn{2}{|c|}{ Day 5} & \multicolumn{2}{|c|}{ Day 10} \\
\hline & E. coli & S. aureus & E. coli & S. aureus & E. coli & S. aureus \\
\hline P-D-A chimera & 5 & 2.5 & 5 & 10 & 5 & 2.5 \\
\hline Pyrrhocoricin & $>40$ & $>40$ & 20 & $>40$ & 40 & $>40$ \\
\hline Pip-pyrr-MeArg dimer & $>40$ & $>40$ & 40 & $>40$ & 20 & $>40$ \\
\hline Magainin 2 & 40 & 40 & 20 & 5 & $>40$ & 40 \\
\hline Kanamycin & 10 & 0.6 & 0.6 & $<0.3$ & 10 & 0.3 \\
\hline Erythromycin & $>40$ & 40 & $>40$ & $>40$ & $>40$ & $>40$ \\
\hline Amoxicillin & $>40$ & $>40$ & $>40$ & 20 & $>40$ & 20 \\
\hline Ciprofloxacin & $<0.3$ & $<0.3$ & $<0.3$ & $<0.3$ & $<0.3$ & $<0.3$ \\
\hline
\end{tabular}

Escherichia coli SEQ102 (full-strength MHB) and Staphylococcus aureus 655 (1/4 strength MHB) strains were subcultured daily with 1.25 and $2.5 \mu \mathrm{M}$ P-D-A chimera, respectively, and the activity of various antibiotics against the mutated strains was determined in day 0 , day 5 and day 10. Increase of the MIC values indicate resistance induction. 
Table V. Reduction of the Antimicrobial Activity of Dimeric Pyrrhocoricin Derivatives in the Presence of 25\% human Serum

Minimal inhibitory concentration in $\mu \mathrm{M}$ when no serum is added / in the presence of $25 \%$ human serum against various strengths of $E$. coli SEQ102, S. typhimurium S2 or $S$. aureus 655 MHB

\begin{tabular}{lcccc}
\hline & \multicolumn{2}{c}{ E. coli SEQ102 } & & S. typhimurium S2 \\
\cline { 2 - 5 } & Full-strength MHB & $1 / 4$ strength MHB & Full-strength MHB & $\begin{array}{c}\text { S. aureus 655 } \\
1 / 4 \text { strength MHB }\end{array}$ \\
\hline P-D-A chimera & $2.5 / 10$ & $2.5 / 40$ & $2.5 />40$ & $5 />40$ \\
P-D construct & $2.5 / 40$ & $2.5 / 10$ & $10 />40$ & $5 />40$ \\
Pip-pyrr-MeArg dimer & $10 / 10$ & $0.6 / 0.6$ & $5 / 40$ & $>40 />40$ \\
\hline
\end{tabular}

The assays were run on single plates, in conditions identical to those representing Figs. 1 and 2 and Table II.

\section{DISCUSSION}

Broad-spectrum antimicrobial peptides were once considered viable therapeutic agents, and indeed cleared different clinical trial phases (Zasloff 2002). These peptides generally kill bacteria by disintegrating the membrane structure. Their selectivity to bacteria originates from the differences between prokaryotic and eukaryotic cell structures. The interaction of most cationic peptides with eukaryotic membranes is inhibited by the lack of negatively charged lipids on the cell surface, by the rather low negative membrane potential that exists across the plasma membrane and also by the presence of cholesterol. In contrast, bacterial membranes are abundant in anionic surface phospholipids, have high negative transmembrane potential and lack cholesterol as a stabilizing force (Hancock and Scott 2000). However the moderate clinical success and therapeutic index of broad-spectrum antimicrobial peptides has made the pharmaceutical industry less than enthusiastic about peptide antibiotics, even if new indications, such as immune stimulatory activities may give a second life to these lead molecules (Bowdish et al. 2004). Interest has slowly shifted to peptides acting on intracellular bacterial targets (Cudic and Otvos 2002) although inactivation of bacterial macromolecules can restrict the pool of peptide-susceptible bacterial strains due to potential sequence modifications of the target proteins (Gennaro et al. 2002). As attractive as the inactivation of intracellular macromolecules is, the current report documents that penetration into bacterial cells is still the rate-limiting step. Pyrrhocoricin is the prototype peptide antibiotic acting inside bacterial cells, but even the most potent purely pyrrhocoricin-based derivative, the Pip-pyrr-MeArg dimer, is inferior to the mixed dimers in killing bacteria in vitro. Drosocin possesses a more aggressive cell-penetrating unit but a less active DnaK-binding domain (Bencivengo et al.
2001), and these structural differences among native antimicrobial peptides are probably due to the identity of the invading pathogens that the flies (D. melanogaster) or the true bugs ( $P$. apterus) have to conquer. The suboptimal pharmacological properties of the P-D-A chimera can be improved by either stabilizing the sensitive bonds, or by selecting another delivery module, from a third insect-derived antimicrobial peptide.

Whatever sequence the final selection will have, it is probably safe to say that the dimeric structure of the chimera has to be retained. On one hand, pyrrhocoricin dimers show reproducibly better cell penetrating properties, hence antimicrobial activities than monomers (Cudic et al. 2002). On the other, a monomeric pyrrhocoricin-drosocin chimera, made up from the N-terminal DnaK-binding half of pyrrhocoricin and the C-terminal delivery module of drosocin is less active than the native constituents alone (Bencivengo et al. 2001). The dimeric structure is likely to provide multiple attachment points to bacterial phospholipids and promote cell entry. Whether the utilized diamino-butyric acid scaffold is the ideal selection to achieve this goal remains to be seen. As far as the rest of the non-natural amino acid residues is concerned, our current studies show that methylation of the C-terminal arginine in drosocin does not seem to improve the serum stability and can be eliminated. Likewise, when the general membrane penetrating ability is high, we found little utility in the positive charge in the ring of the amino-piperidinecarboxylic acid residue, and the much simpler cyclic valine mimic amino-cyclohexane carboxylic acid appears to work just fine. Having said this, a non-natural amino acid residue cannot be fully eliminated from the amino terminus in order to avoid non-specific interaction with the conventional substratebinding pocket of $\mathrm{Hsp} 70$ proteins. Although pyrrhocoricin binds at least 4-5-fold more strongly to the bacteria-specific D-E helix site than to the 
non-specific pocket, interaction of pyrrhocoricin with all Hsp70 proteins through interaction with the evolutionally conserved substrate-binding pocket is always a concern (Chesnokova et al. 2004). Such an interaction can lead to toxicity to the host when heat shock protein production is upregulated upon bacterial infection (Kragol et al. 2002).

Indeed, nature designed the native antibacterial peptides to bind many macromolecular structures and surfaces. The alternating hydrophobic-cationic residue architecture and the dimeric composition allows maximum interaction with the bipolar phospholipid layer of bacterial membranes. Yet the same architecture makes these peptides very sticky compounds and this structural feature often hinders assays designed to evaluate peptide-peptide binding reactions. As fluorescence polarization could not be used to quantitate the binding strength of labeled dimers to the synthetic D-E helix fragments of E. coli and $S$. aureus DnaK (see Results), we tried the opposite, looking for antibacterial peptide dimer binding to biotin-labeled DnaK fragments. However, the sticky nature of the dimers prevented these efforts. Regardless of whether we used biotin-labeled DnaK fragments as capture molecules on streptavidin-coated Ciphergen chips, or detectors during Western-blotting, peptide-peptide binding was repeatedly detected in not only those cases when biological results did not support any interaction (e.g. the Pip-pyrr-MeArg dimer to S. aureus DnaK D-E helix), but even to blank Ciphergen chips or unrelated control peptides (e.g. a p53 tetramerization domain) on the Western-blot. Therefore, to document dimer binding to DnaK, we have to rely on the study involving the full protein shown here in Fig. 3. Because both the Pip-pyrr-MeArg dimer and the P-DA chimera bound E. coli DnaK in a highly similar manner (with an identical $K_{\mathrm{d}}$ of $4 \mu \mathrm{M}$ ), with the latter peptide significantly more active against $E$. coli cultures in full-strength $\mathrm{MHB}$, we conclude that while the Pip-pyrr-MeArg dimer kills bacteria only inactivating DnaK, the P-D-A chimera additionally destroys the bacterial membrane structure. The activity against $S$. aureus, a bacterium which possesses a DnaK sequence unsuitable to bind pyrrhocoricin (Kragol et al. 2001, 2002) supports this hypothesis.

One potential additional way to tell whether killing microorganisms proceeds through membrane disintegration or inhibition of intracellular targets is the measurement of the kinetics of the growth inhibition reaction. While rapid killing indicates membrane depolarization, killing over an extended period of time is a sign of inhibition of intracellular target molecules. Drosocin, for example, in this measure inhibits bacterial growth only after $6 \mathrm{~h}$ of treatment as opposed to diptericin, a more distant family member with a high glycine content that kills bacteria within 45 min (Cudic et al. 1999). The original report on pyrrhocoricin used peptide material isolated from insects, disk growth inhibition assay and the laboratory strain E. coli D22 (Cociancich et al. 1994) to detect antimicrobial activity only $6 \mathrm{~h}$ after peptide addition, with full killing over a 24-h period. E. coli D22 has a compromised outer membrane structure, which is clearly different from that of clinical isolates, such as the urinary-tract infection originated E. coli SEQ102, a strain that developed resistance to nonpeptidic antibiotics (Cudic et al. 2003). In our hands, the first time point when the liquid growth inhibition assay presented quantifiable growth of E. coli SEQ102 or $S$. aureus 655 was $2 \mathrm{~h}$; however by that time period all pyrrhocoricin-based antibacterial peptides killed the bacteria (in cases when they would kill overnight). While with this assay we could not identify differences in the mode of action of the various pyrrhocoricin-based antimicrobials, we were able to more accurately estimate the killing period, which is less than $2 \mathrm{~h}$. This time period is still enough to inhibit DnaK-associated protein refolding in bacterial cells as indicated by assaying the enzymatic activity of E. coli cultures (Kragol et al. 2001).

Drosocin's improved cell penetrating properties can be used for delivery of peptidic and non-peptidic drug leads into cells. Recently we showed that the Pip-pyrr-MeArg chimera enters a long range of bacterial and mammalian cells and is a useful delivery vehicle of peptide epitopes into dendritic cells (Otvos et al. 2004). While neither the antibacterial peptide derivative nor a cytotoxic $\mathrm{T}$ cell epitope alone activated human dendritic cells, a construct made of these two constituents resulted in the appearance of maturation markers in $65 \%$ of the dendritic cells studied. We explained these findings with the ability of the strongly cationic Pip-pyrr-MeArg dimer to utilize the less abundant (than in bacteria), but still present negative charges on the eukaryotic cell surface to enter mammalian cells via passive transport (Otvos et al. 2004). Alternatively, the antibacterial peptide can collect extracellular Hsp70 and enter cells through interaction with the Hsp70 receptor CD91 molecules abundant on the surface of immune cells (Srivastava 2002) and thus, active transport. In any event, the improved bacterial cell penetrating abilities of the pyrrhocoricin-drosocin mixed chimeras are 
likely to represent further improved drug delivery properties into eukaryotes and across epithelial cell layers. The only disadvantageous feature of drosocinbased peptides, the low stability in biological media, can actually come in handy if used as drug delivery vehicles. We had to pay special attention to select linkers between the peptide epitopes and the antibacterial peptide delivery units that are cleavable in the intracellular milieu, after cell penetration is completed (Otvos et al. 2004). With the observed rapid degradation of drosocin derivatives, they may serve as self-destroying drug delivery modules.

In summary, here we present a new concept for antibacterial peptides. With chimeras designed to kill bacteria by a combination of DnaK inhibition and membrane disintegration we managed to identify a class of antimicrobials that kill bacteria with a dual mode of action. Such combinatorial effect not only improves the activity spectrum and efficacy of the short, proline-rich antibacterial peptide family, but represents a treatment option against bacterial strains that are prone to develop resistance to individual antimicrobial agents.

\section{ACKNOWLEDGEMENTS}

This work was supported by the Commonwealth Universal Research Enhancement Program, Pennsylvania Department of Health.

\section{REFERENCES}

Andreu, D. and Rivas, L.: 1998, Biopolymers. 47, 415-433.

Bencivengo, A.-M., Cudic, M., Hoffmann, R. and Otvos, L. Jr.: 2001, Lett. Pept. Sci. 8, 201-209.

Boman, H. G.: 1995, Annu. Rev. Immunol. 13, 61-92.

Bowdish, D. M., Davidson, D. J., Speert, D. P. and Hancock, R. E.: 2004, J. Immunol. 172, 3758-3765.

Bower, M. A., Cudic, M., Campbell, W., Wade, J. D. and Otvos, L., Jr.: 2003, Lett. Pept. Sci. 10, 466-473.

Bulet, P., Dimarcq, J.-L., Hetru, C., Lagueux, M., Charlet, M., Hegy, G., van Dorsselaer, A. and Hoffmann, J. A.: 1993, J. Biol. Chem. 268, 14893-14897.

Bulet, P., Urge, L., Ohresser, S., Hetru, C. and Otvos, L. Jr.: 1996, Eur. J. Biochem. 238, 64-69.

Casteels, P. and Tempst, P.: 1994, Biochem. Biophys. Res. Commun. 199, 339-345.

Casteels, P., Ampe, C., Jacobs, F., Vaeck, M. and Tempst, P.: 1989, EMBO J. 8, 2387-2391.

Casteels, P., Romagnolo, J., Castle, M., Casteels-Josson, K., Erdjument-Bromage, H. and Tempst, P.: 1994, J. Biol. Chem. 269, 26107-26115.
Castle, M., Nazarian, A., Yi, S.-S. and Tempst, P.: 1999, J. Biol. Chem. 274, 32555-32564.

Chesnokova, L. S., Slepenkov, S. V. and Witt, S. N.: 2004, FEBS Lett. 565, 65-69.

Cociancich, S., Ghazi, A., Hetru, C., Hoffmann, J. A. and Letellier, L.: 1993, J. Biol. Chem. 268, 19239-19245.

Cociancich, S., Dupont, A., Hegy, G., Lanot, R., Holder, F., Hetru, C., Hoffmann, J. A. and Bulet, P.: 1994, Biochem. J. 300, $567-575$.

Cudic, M. and Otvos, L. Jr.: 2002, Curr. Drug Targets. 3, 101-106.

Cudic, M., Bulet, P., Hoffmann, R., Craik, D. J. and Otvos, L. Jr.: 1999, Eur. J. Biochem. 266, 549-558.

Cudic, M., Condie, B. A., Weiner, D. J., Lysenko, E. S., Xiang, Z. Q. O. I., Bulet, P. and Otvos, L. Jr.: 2002, Peptides. 23, 2071-2083.

Cudic, M., Lockatell, C. V., Johnson, D. E. and Otvos, L. Jr.: 2003, Peptides. 24, 807-820.

Devine, D. A. and Hancock, R. E.: 2002, Curr. Pharm. Des. 8, 703714.

DiNardo, A., Vitiello, A. and Gallo, R. L.: 2003, J. Immunol. 170, 2274-2278.

Fields, G. B. and Noble, R. L.: 1990, Int. J. Pept. Protein Res. 35, 161-214.

Finlay, B. B. and Hancock, R. E. W.: 2004, Nat. Rev. Microbiol. 2, 497-504.

Friedrich, C. L., Moyles, D., Beveridge, T. J. and Hancock, R. E.: 2000, Antimicrob. Agents Chemother. 44, 2086-2092.

Gallo, R. L. and Huttner, K. M.: 1998, J. Invest. Dermatol. 111, 739-743.

Gennaro, R., Zanetti, M., Benincasa, M., Podda, E. and Miani, M.: 2002, Curr. Pharm. Des. 8, 763-778.

Hancock, R. E. W. and Scott, M. G.: 2000, Proc. Natl. Acad. Sci. USA. 97, 8856-8861.

Hoffmann, R., Bulet, P., Urge, L. and Otvos, L. Jr.: 1999, Biochim. Biophys. Acta. 1426, 459-467.

Kragol, G., Lovas, S., Varadi, G., Condie, B. A., Hoffmann, R. and Otvos, L. Jr.: 2001, Biochemistry. 40, 3016-3026.

Kragol, G., Hoffmann, R., Chattergoon, M. A., Lovas, S., Cudic, M., Bulet, P., Condie, B. A., Rosengren, K. J., Montaner, L. J. and Otvos, L. Jr.: 2002, Eur. J. Biochem. 269, 4226-4237.

Ludtke, S., He, K. and Huang, H.: 1995, Biochemistry. 34, 16764 16769.

Mackintosh, J. A., Veal, D. A., Beattie, A. J. and Gooley, A. A.: 1998, J. Biol. Chem. 273, 6139-6143.

McManus, A., Otvos, L. Jr., Hoffmann, R. and Craik, D. J.: 1999, Biochemistry. 38, 705-714.

Meister, M., Lemaitre, B. and Hoffmann, J. A.: 1997, BioEssays. 19, 1019-1026.

Otvos, L. Jr.: 2000, J. Pept. Sci. 6, 497-511.

Otvos, L. Jr., Bokonyi, K., Varga, I., Otvos, B. I., Hoffmann, R., Ertl, H. C. J., Wade, J. D., McManus, A. M., Craik, D. J. and Bulet, P.: 2000a, Protein Sci. 9, 742-749.

Otvos, L. O. I. Jr., Rogers, M. E., Consolvo, P. J., Condie, B. A., Lovas, S., Bulet, P. O. I. and Blaszczyk-Thurin, M.: 2000b, Biochemistry. 39, 14150-14159.

Otvos, L. Jr., Cudic, M., Chua, B. Y., Deliyannis, G. and Jackson, D. C.: 2004, Mol. Pharmaceut. 1, 220-232.

Scott, M. G., Davidson, D. J., Gold, M. R., Bowdish, D. and Hancock, R. E. W.: 2002, J. Immunol. 169, 3883-3891.

Srivastava, P.: 2002, Annu. Rev. Immunol. 20, 395-425. 
Steiner, H., Andreu, D. and Merrifield, R. B.: 1988, Biochim. Biophys. Acta. 939, 260-266.

Urge, L. and Otvos, L. Jr.: 1995, Lett. Pept. Sci. 1, 207-212.

Uttenweiler-Joseph, S., Moniatte, M., Lagueux, M., Van Dorsselaer, A., Hoffmann, J. A. and Bulet, P.: 1998, Proc. Natl. Acad. Sci. USA. 95, 11342-11347.

Wieprecht, T., Apostolov, O., Beyermann, M. and Seelig, J.: 2000, Biochemistry. 39, 442-452.

Wimley, W. C., Selsted, M. E. and White, S. H.: 1994, Protein Sci. 3, 1361-1373.
Wu, M., Maier, E., Benz, R. and Hancock, R. E. W.: 1999, Biochemistry. 38, 7235-7242.

Yang, D., Chen, Q., Schmidt, A. P., Anderson, G. M., Wang, J. M., Wooters, J., Oppenheim, J. J. and Chertov, O.: 2000, J. Exp. Med. 192, 1069-1074.

Zasloff, M.: 2002, Nature. 415, 389-395.

Zhang, L., Benz, R. and Hancock, R. E. W.: 1999, Biochemistry. $38,8102-8111$. 